\title{
IF IT IS NOT TOO LATE - LET'S PRESERVE OUR Planet For the NeXt Generations
}

\author{
ELISEEV, ALEXEY S.
}

Abstract: Time is passing and humans are understanding deeper and deeper that Earth is the only place in the Universe where they can live and that Earth should be protected. Until now, the attitude of people to Earth's resources was not prudent. Now, nature is rapidly degrading and this process has become dangerous for humans. Many people are thinking how to correct the state or affairs. Author has decided to share his thoughts with the readers regarding this topic.

Key words: ecology, earth, preservation, sustainable development, environment
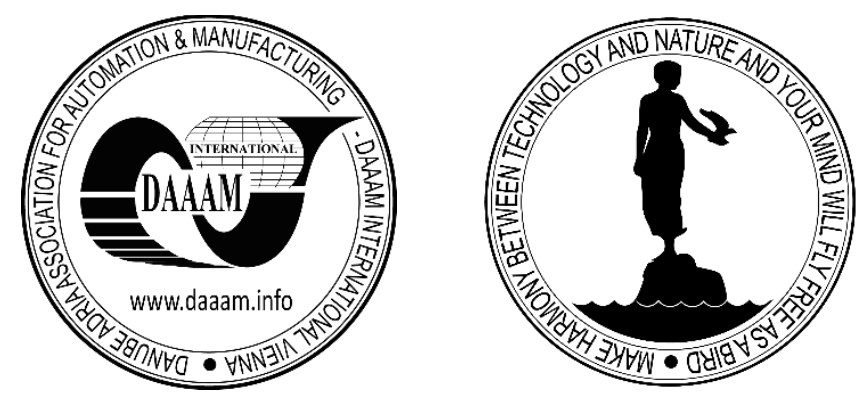

Authors' data: A[lexey] S. Eliseev, Professor, Cosmonaut \& Master of Sport

This Publication has to be referred as: Eliseev, A[lexey] (2016). If it Is Not Too Late: Let'S Preserve Our Planet for the Next Generations, Chapter 01 in DAAAM International Scientific Book 2016, pp.001-010, B. Katalinic (Ed.), Published by DAAAM International, ISBN 978-3-902734-09-9, ISSN 1726-9687, Vienna, Austria DOI: $10.2507 /$ daaam.scibook.2016.01 


\section{Introduction}

In the language of scientists, we (humans) present only one from numerous biological species. Now on Earth, there are about 8,5 million different species and we are one of them. These species are arriving into the common flow of biological life where favorable conditions for their existence are being created and are leaving this flow when such conditions are disappearing. From the moment when biological life originated, around 500 million species have already left our planet.

If we extrapolate the history into the future, we shall come to the conclusion that humans will also leave sooner or later because the conditions for their existence will vanish. But the difference between humans and other species consists in the human ability to control many of those conditions which are necessary to support their life. It means that the duration of human existence depends on humans themselves and on their interaction with the surrounding nature.

Many of us would like to believe that humans will do everything correctly and will provide a successful stay for their species in this world as long as it is possible. It would be well to realize that we all together, generation after generation, are creating a civilization which is permanently developing and is understanding the Universe deeper and deeper, enlarging its participation in it. Unfortunately, humans haven't taken this route so far.

Humans have taken a particular position among other biological species because they have a greater intellect. Thanks to the ability to think, humans have learned to create tools and to apply them, started to use natural resources in much larger scale than it is attainable for animals. In time the tools were becoming more and more sophisticated and the scale of natural resources consumption was growing. For a long time, nature was compensating losses caused by human activity without changing its natural way of development. But such time has expired, the losses became too large and the nature was forced to restructure itself. At this stage, nature started to lose the very same content and properties, which have formed the appearance of humans.

According to scientist data, by the end of last century the development of nature had crossed the "border of equilibrium" - the state of nature, at which losses of its properties, caused by human activity and important for human life, are equal to nature's ability to compensate such losses (Tambroni \& Seminara,, 2012). Now the losses are not being compensated and conditions for human life are worsening. Moreover, the state of nature is already becoming a threat to next generations, even for those young people who are already born. Signs of these dangerous processes became already evident. To change the course of events, humans have to radically restructure their relations with the nature and without waste of time.

Humans were gradually approaching to the current situation. At the beginning of their existence, humans considered nature's resources as inexhaustible. After that, having understood that resources are limited, humans worried more about their own well-being than the well-being of next generations.

It is clear that during the initial period of existence human interests were very close to animal interests. Humans, like animals were thinking mostly about provisioning themselves with food and lodging. But thanks to better intellect, humans 
were reaching their goals more effectively - for example, the use of tools at hunting. This method gave them an advantage over animals. Therefore, it became easier to conquer animals and consequently animal extermination started to grow (Zawistowski et al., 1998). The nature was slightly changing in favor of humans. Of course, in that period people were not thinking about future of mankind. But nevertheless, they had already unconsciously started to form that future.

A great significance for relations between people and nature was the beginning of land cultivation and animal breeding as shown in Fig.1.. From collection of wild plant fruits, humans went over to purposeful cultivation of needed cultures, from hunting to breeding animals, which were used as source of meat. Having made these steps, humans interfered into the native way of nature development (Bronfenbrenner, 2009). Cultivating the needed cultures and breeding needed animals on the selected plots of land people started to change the quantitative ratios of biological species on these plots. It means they started to locally restructure the nature - the very same nature which had provided satisfactory conditions for human life. Henceforth this process of restructuring was being developed. Gradually it acquired a large scale and became crucial for people.

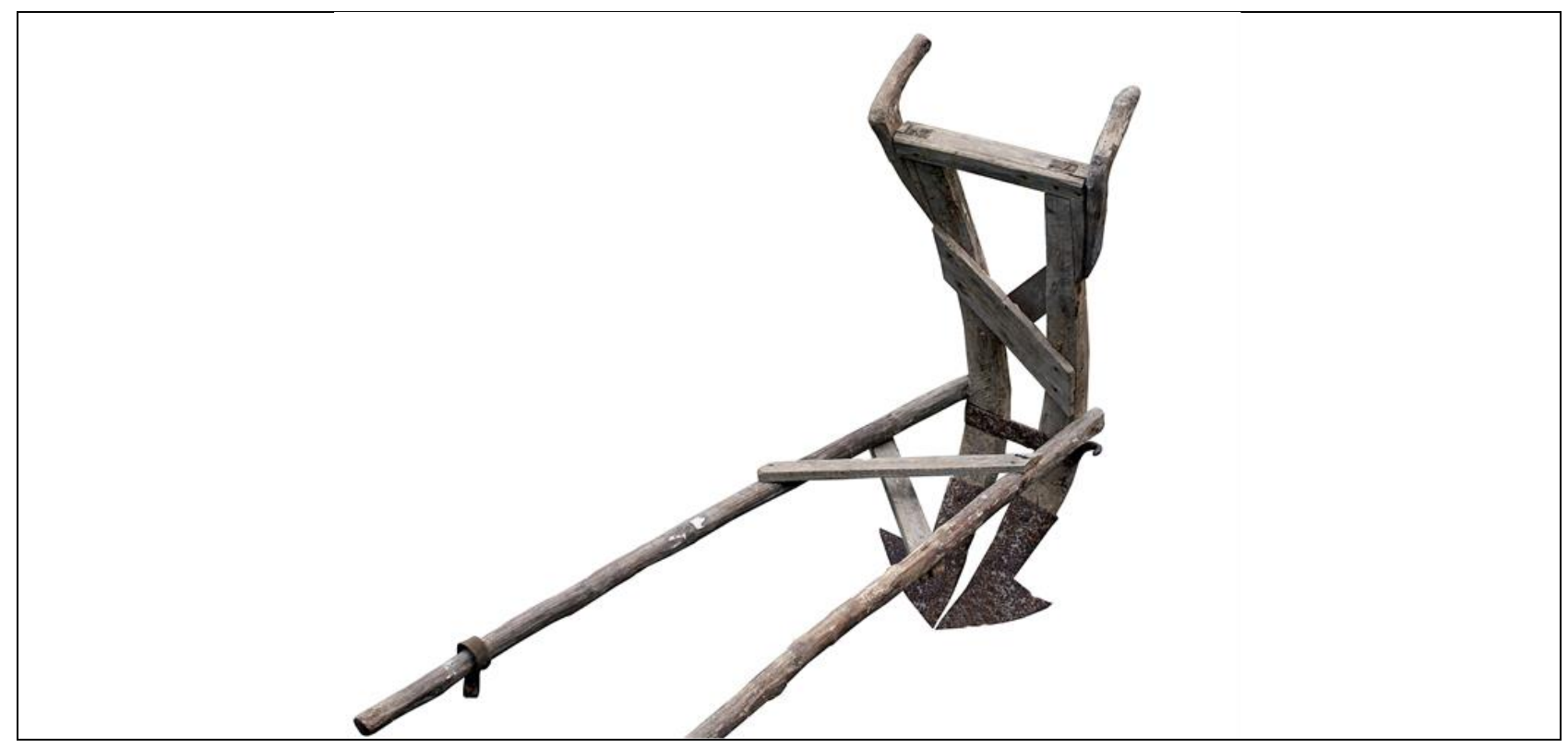

Fig. 1. Cultivation tools.

It is quite natural that humans were always striving to improve their living conditions. In different settlements and even within one same settlement, different people realized their wishes in different ways. Therefore, different people created different products. Guided by the desire to create best conditions for themselves people had started to exchange created products with each other. Trade had started and created an incentive for people to specialize their labor. This made it possible to receive the biggest possible amount of desired products for themselves in case of an exchange. The labor was becoming more productive and the consumption of natural resources was growing.

At a certain point humans invented money. Use of money gave an opportunity for a person to split the procedure of exchange in two parts: selling and purchasing. 
Now a person could sell a product of his (her) labor and keep the money until he (she) would need to buy products produced by somebody else. Availability of money was creating a confidence in the future wellbeing. By accumulating money, a person was increasing the stability of his wellbeing. Because of this, money became a powerful incentive for production of products intended for sale. The quantity of products in the trade area began to grow. Along with this, the average consumption per person was also growing. To produce products people were consuming natural resources. Consequently, the natural environment was suffering growing losses.

Another factor, which was increasing the load on nature, was the population growth. Wellbeing and population size were tied up with each other in such a way that the growth of one of these parameters caused the growth of another one. The better life was, the higher the birth rate was. When the birth rate was increasing the number of working hands was also increasing, volume of production was growing and life conditions were being improved. Because of such links, both the number of people and the consumption of natural resources were growing with acceleration.

As experience was being accumulated, humans were realizing more and more that tools are playing a very important role in their life. By using tools, the humans could work more effectively and spend less energy. In the market conditions it was possible to change tools for consumer goods and the more sophisticated the tool was, the bigger quantity of consumer goods could be received for it. People started to design and to manufacture tools purposefully for the market. Their activity in this direction led them to machine invention. Machines were making human labor many times more productive, compared with labor using manual tools. In some cases, machines were running production processes without any people participation.

The invention of machines exerted the biggest influence on production development. Utilization of machines led to rapid rise in quantity of goods and opened new possibilities for transportation. People saw the benefits of machines and were investing much efforts in their production and development. Industrial revolution had started. It was giving birth to factories which were producing consumer goods and to factories which were producing machines. At such production possibilities people were creating power plants, electric lines, railway transport, cars. The load on the nature was growing rapidly. First of all, the consumption of natural resources was being rapidly increased. Additionally, there were losses of territories, where people were building factories and roads. On these territories significant part of biological life was being killed.

Humans always intended to increase their possibilities for current and future consumption and to improve living conditions. For these purposes humans were striving to increase their personal wealth. On the government level it was believed that a country is wealthier when its people are wealthier. To support intentions of the people, scientists and politicians in different countries were looking for ways to increase personal and common possessions. There was one event which exerted a significant influence on this search.

At the time when the machines appeared, the Scottish economist Adam Smith published his book "The Wealth of Nations". In this book he proposed measures which would put the country on the way of fast enrichment (Smith, 1937). The author deemed 
that people in their economic life are being guided by the feeling of egoism (Leary, 2004). To make a country rich, in his opinion, it was necessary to create the most favorable conditions for each person by satisfying this egoistical feeling. The author believed that maximum freedom of the market would solve this task. In this he saw the key for development. When the book was being written there were no yet evident signs that resources of nature might be exhausted. Possibly, for this reason, the book does not contain any remarks concerning the necessity to take the state of environment into account.

The book was studied in many countries. It stimulated great interest and seemed convincing. The Smith's call was accepted. In some countries his book became almost a guide to actions. Where Smith's ideas found realization, production and entrepreneurial activities were growing. Scale and effectiveness of machines application were also going up. Correspondingly, the load on nature was again increasing.

Getting acquainted with the human history, we can recognize the accelerated development of human knowledge and skills. Such conclusion can be reached, for example, on the ground of the following historical comparisons: time interval between wheel invention and bearing invention was around 4000 years: interval between bearing invention and sewing machine invention was approximately 350 years: interval between sewing machine invention and creation of the first automated car assembly line was only 70 years.

Simultaneously with technology development, materialistic standard of living was increasing. As a response to this, the population was also growing. Since the beginning of the industrial revolution (about 1760) until now, the world output increased 600 times and the population approximately 9 times. These changes have been occurring for approximately 250 years. The period which is equal to one tenthousandth part of the whole time of human existence (if counting from Homo erectus). It is one moment in history.

During this "moment" the nature has lost a lot. Agricultural fields, cities, roads, power lines, dumps had occupied the land which was formerly covered with wild plants. Approximately one half of the forest which existed on our planet before the revolution has disappeared. The rainforest has lost more than half. We know that both forests are habitats of many animal species, they consume a great part of carbon dioxide and have a strong influence on the climate.

Now almost one quarter of biologically productive land is occupied by agricultural farms. On this land chemical fertilizers are being used and natural biological life is reduced. The products which are being produced by many farms today are different from those which were grown in natural conditions. They have different taste and different nutritional qualities.

Significant changes have occurred in the atmosphere. Factories, power stations, transport vehicles are releasing carbon dioxide, solid particles and even poisonous substances. Concentration of these contaminants is growing. To burn the fuel, industrial and transportation means are consuming oxygen and in many cities its concentration in the air has started to decline. 
Changes in the atmosphere are being transmitted to the soil. Harmful contaminants are falling to the ground together with rains and this exerts additional harmful effects on the biological life of soil.

Water is also suffering. A great part of industrial and domestic waste is being discharged into the water as shown in Fig. 2. For this reason, in many rivers and lakes, water turned from drinkable to non-drinkable and somewhere fish is vanishing. At the same time with population growth, demand for fish is also growing. As the demand is increasing fishing is being intensified and the total volume of fish catch is rising. Today the catch is more than the appearance of new fish due to reproduction. The quantity of fish in oceans is decreasing. According to forecasts if people don't take effective measures aimed to protect water against contamination and to limit the size of catching, in 25-30 years the total amount of fish in the oceans will be twice less than it is today.

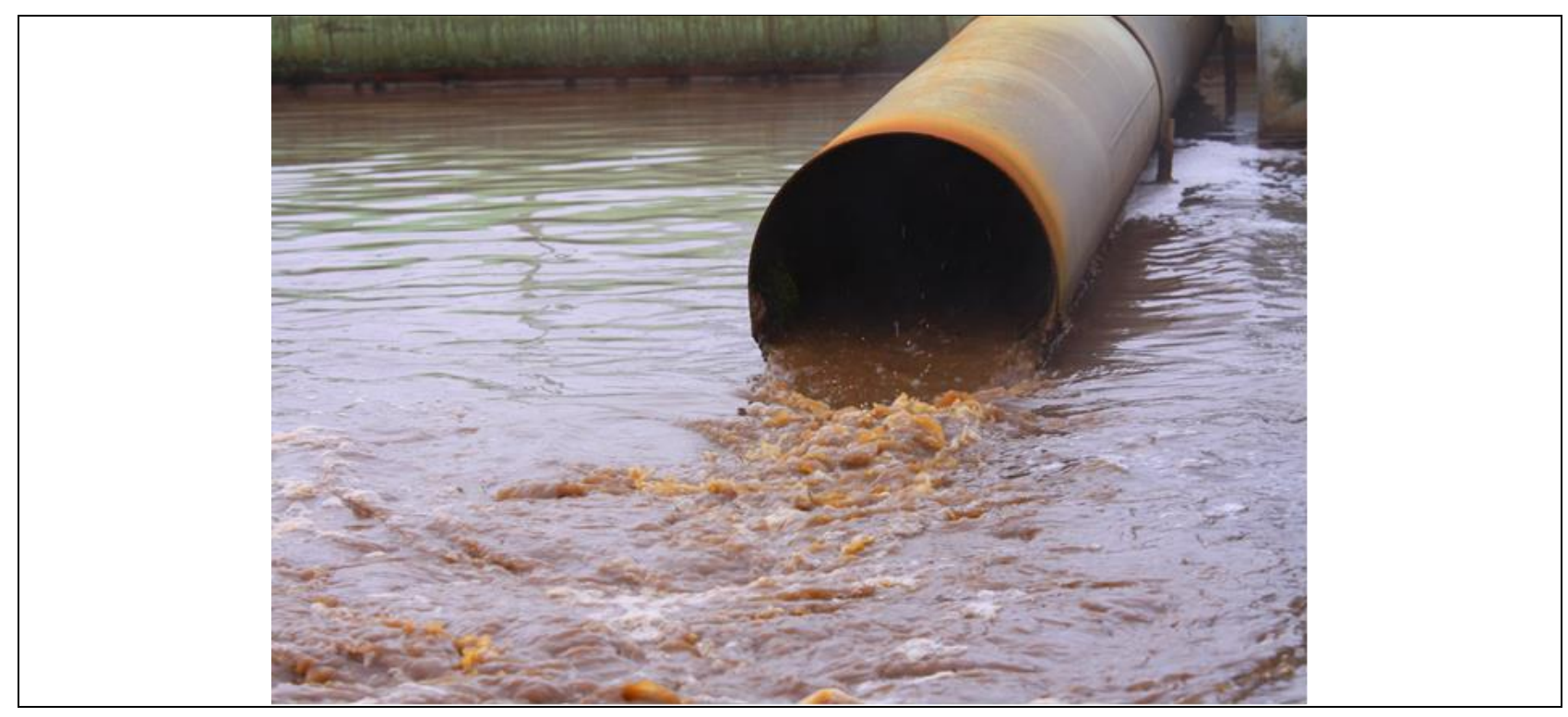

Fig. 2. Water pollution

It is quite obvious that changes which are taking place in water. air and soil are affecting the biological life of the whole planet, including biological life of humans. Unfortunately, human body is not adapting to these changes. It inherited biological mechanisms from ancestors and reacts painfully when environment becomes different. Today in the world, millions of people are dying every year due to diseases caused by environment pollution. And these losses are growing (Thorsheim, 2006).

The current state of the environment shows that we entered a dangerous zone (Goodstein, 2011). The situation is being complicated by the fact that at such intensive use of natural resources people do not have enough food. Hundreds of thousands of people die from starvation every year (Cohen, 1977).

Now scientists and politicians are paying great attention to changes in the environment (Dunlap et al.,2012). For practical reasons among the losses, which have already happened, a special interest should be directed to those, which theoretically can be restored, completely or partially, in a reasonable time. First of all, losses in air, water and soil. People are also using many other resources, for example coal, oil, gas, metals, uranium, diamonds. Restoration time of such resources is incomparably more than the 
duration of human life. For the time being there is no sense to talk about human participation in their restoration. We may only hope that by the time when the natural reserves of such components will be exhausted people will find a substitute for each of them.

Reflecting on the situation in which today we all found ourselves, everybody may unintentionally come to the conclusion that humans until now were using the nature imprudently. Before consumption of resources or before disposing waste, humans had to learn to what consequences that would lead. Ideally humans had to continually forecast nature reactions based on the interaction with it. They had to know what was anticipated and to organize their activity in such a way that the state of the nature would not be deteriorated.

People failed to build mutually acceptable relationship with nature. For a long time, they have not seen the danger of the way they were going. They were not realizing necessity to strictly adapt their behavior with nature's reaction to that behavior. Their primary aspirations were always and still are to increase the wealth.

We see that a mechanism with positive feedback is functioning in relationship between humans and nature: the more humans are taking from the nature the richer they become and the growth of wealth stimulates humans to increase takings again (Munasinghe, 1999). If a process with such feedback is not stopped the system will collapse. Most likely something similar should happen in biology too.

Nowadays, behavior of the whole human community in a sense is similar to behavior of an addict. People are striving to take from nature as much as possible to live now and as well as possible. Many people realize that such behavior is leading to sad results.

Of course people are taking some measures to protect the nature: there are quotas on emission of harmful gases into the atmosphere, there are administrative restrictions on the way of deforestation, factories are installing channel filters for the discharge of production waste. But these measures are not enough. These measures are only slowing down the process of nature degradation but are not stopping it (Baland \& Platteau, 1996).

To stop degradation and to come to balance between human impacts on nature and nature's possibilities to compensate these impacts without losses for itself, humans have to change their way of life (Panayotou, 1993). Understanding that nature, not computers and mobile phones, gives humans the opportunity to live, should be the basis of human activity. Human life is a set of biological processes, which are supported by nature. Functioning of the brain, including thinking, is a part of these processes. This part produces the impression that we are living.

It seems that transition to a new way of life will require joint solution of three main tasks: to restore the nature up to the balance state, to reduce general consumption of natural resources and to stop population growth. All these tasks are very difficult. Probably while they are being solved, technical progress in traditional areas will slow down. The priority of development will move from means of consumption to means of nature restoration. But these changes will not make life less interesting. Simply some interests will move from one area to another. We know from history that life was always interesting - in the era of Socrates, when Leonardo da Vinci was living, in the 
time of Tsiolkosky. People are interested to learn new things and opportunities for that are everywhere. People will not suffer if new appliances for their work and life do not appear as often as today. Absence of what does not exist is not making human life less interesting. People of older generations were not suffering for the reason that being students they didn't have computers. Today we are not suffering for the reason that we don't have devices which will appear in the future.

Speaking about a new way of interaction with nature we have to keep in mind the nature of our whole planet, not some parts of it. It means that all habitants of the planet should follow some common rules. The atmosphere is common for all and all together have to protect it from pollution. People are eating fish everywhere, hence all together have to keep the needed stock of fish in oceans. The problem is: how to organize such unity?

Around 30 years ago Russian physicist and Nobel prize winner A.D.Sacharov expressed the idea that the time has come when all people should unite and live together in accordance with a common world constitution (Sakharov, \& Salisbury, 1971). At that time his idea was taken for utopia but new scientific results in ecology, biology and medicine make us return to it. It looks like his idea shows the right basis to establish normal relationship between people and nature. And probably it's time to accept his idea before it will be too late.

Realization of A.D.Sacharov's idea doesn't mean that all borders between countries should be instantly eliminated and a world government should be appointed tomorrow. It means that people defined the goal, charted a way of movement to this goal and started to act. We may imagine that on initial stage country leaders will create a world coordination center, will define a few administrative areas made up of several countries each and will start to implement new rules inside these areas.

Creation of common relationship rules between humans and nature is a very complicated task. These rules should be acceptable for all people, but in different countries culture and customs are different. It will be necessary to find compromises. Direct experiments with participation of many people are not possible. Scientists have only methods of mathematical simulation at their disposal. But average human activity can only be approximated with a mathematical description. The rules should be searched not only for the time of balanced life, but for the transition period from nowadays till that time as well.

There are probably "optimists" who believe that there is no reason to worry. We may continue to move without radical changes. People will continue to change nature, the nature will change people and a mutual adaptation will take place between these two participants of biological life. Unfortunately, it is not happening. The nature is rapidly degrading and because of this reason our contemporaries have started to die prematurely.

Of course, the realization of A.D.Sacharov's idea is a super complicated task and only very strong politicians can tackle it. There will be many protesters. Perhaps rich countries will object because they will have to spend part of their wealth for common interests. Businessmen who are earning money on exploitation of natural resources will resist. Finally, there are people who don't understand the danger of the situation and don't want to lose their independence. 
But the history is telling us that development of civilization is going in this direction. In the beginning people were living in tribes. Then tribes united in ethnic groups. After that states appeared. It is quite possible that now is a good time to make the next step - to start the amalgamation of states.

After amalgamation, the states will not have the necessity to spend natural resources to defend borders. First of all, it relates to military spending. Today hundreds of thousands of factories are producing military equipment. Each of these factories is consuming natural resources and polluting environment and each of them is occupying a part of the Earth's surface. During weapon tests, during training of soldiers, and particularly in course of military operations, surface layer of land is being physically destroyed. Biological life in this layer is being killed. After amalgamation all these losses will stop. Now hundreds of millions of people are busy working in munitions factories and serving in armies. These people may be used for nature restoration.

It is evident that load on the nature cannot be decreased only by rearrangement of human resources. The main part of the load is associated with human life - food production. This part is practically proportional to the number of people. Therefore, the fate of mankind will depend on the human ability to control their number.

Now the number of people exceeded the admissible limit and it continues to grow rapidly. During the period from 2000 to 2010 the population grew by 766 millions of people - it is more than the population of all European countries combined. To provide food for such number of people at the average level it would be needed to use as much land as all European countries are now using for agricultural purposes. Such amount of land cannot be taken from somewhere without irremediable damage for the nature. Almost the same growth of population has been predicted for the period from 2010 to 2020. It means that we should expect an increase of food deficit and a number of hungry people.

The experience of China showed that limitation of population grow by administrative measure is a hard problem. Even within one state it was not solved yet. Sometimes the population size is stabilizing naturally. For example, such stabilization had taken place with native population of some European countries. But on the planet such groups of people constitute only a small part. We may expect that amalgamation of the states will lead to world integration of different cultures, but this will hardly lead to the needed decrease of average birth rate. To decrease the birth rate on the global scale, humans have to have possibilities to control the birth rate on the global scale.

To maintain satisfactory living condition, humans have to control not only the birth rate but also the whole human life support system - nature of the planet. Only when understanding or believing in this truth will be prevailing in all countries, amalgamation of countries on this basis will be possible. People have to believe that such amalgamation will be rewarding for them and fateful for the next generations.

People's faith may be based on their knowledge or it may appear because other people have convinced them. To acquire knowledge people, have to get education and to spare time for self-education. Now, this way is not available to all. If only this way is used, people will hardly achieve a general understanding of the situation during the lifetime of one generation. The way of convincing may prove to be more effective, especially if this way will be used by religious organizations. 
All religions are preaching well-behaved life of people and all of them could expand the concept of good behavior if they include it into people's attitude towards nature. Religions have appeared long time ago. At their appearance the nature was being considered as something eternal which would always provide proper conditions for human life and would be always available for humans. At such understanding the nature was not requiring a special care about it. Now people know much more about nature. We have understood that in our relations with nature we should not use the way which our predecessors used. We have to find a new way. It would be good to explain that in sermons. Most people are believers. Many believers realize what is going on. Preachers could help others to also come to that understanding. If it happens the opinion about necessity of changes will dominate in the world.

State educational systems and religions together can create a good basis for redirecting mankind to more reliable way of development than people are doing now.

\section{References}

Smith, A. (1937). The wealth of nations [1776] na.

Sakharov, A. D., \& Salisbury, H. E. (1971). Progress, Coexistence, and Intellectual Freedom

Tambroni, N., \& Seminara, G. (2012). A one-dimensional eco-geomorphic model of marsh response to sea level rise: Wind effects, dynamics of the marsh border and equilibrium. Journal of Geophysical Research: Earth Surface, 117(F3)

Munasinghe, M. (1999). Is environmental degradation an inevitable consequence of economic growth: tunneling through the environmental Kuznets curve. Ecological economics, 29(1), 89-109

Leary, M. R. (2004). The curse of the self: Self-awareness, egotism, and the quality of human life. Oxford University Press

Bronfenbrenner, U., \& Bronfenbrenner, U. (2009). The ecology of human development: Experiments by nature and design. Harvard university press

Baland, J. M., \& Platteau, J. P. (1996). Halting degradation of natural resources: is there a role for rural communities?. Food \& Agriculture Org.

Panayotou, T. (1993). Empirical tests and policy analysis of environmental degradation at different stages of economic development (No. 292778). International Labour Organization.

Goodstein, E. S. (2011). Economics and the Environment. Wiley,.

Thorsheim, P. (2006). Inventing pollution: coal, smoke, and culture in Britain since 1800. Ohio University Press.

Cohen, M. N. (1977). Food crisis in prehistory: overpopulation and the origins of agriculture.

Zawistowski, S., Morris, J., Salman, M. D., \& Ruch-Gallie, R. (1998). Population dynamics, overpopulation, and the welfare of companion animals: new insights on old and new data. Journal of Applied Animal Welfare Science, 1(3), 193-206.

Dunlap, R. E., \& Jorgenson, A. K. (2012). Environmental problems. The WileyBlackwell Encyclopedia of Globalization 